\title{
A new species of the genus Ocenebra Gray, 1847 (Gastropoda Muricidae Ocenebrinae) from southern Spain (Mediter- ranean Sea)
}

\author{
Brian Cunningham Aparicio
}

University of Murcia, Biology Faculty. Puerto de Mazarrón, Murcia, 30860, C/ Aconcagua 11, Spain; e-mail: cabrian98@yahoo.es

\begin{abstract}
Based on morphological characters of the shell and animal, a small new species of gastropod of the genus Ocenebra Gray, 1847 (Gastropoda Muricidae Ocenebrinae), Ocenebra aparicioae n. sp., is here described from the infralittoral coast of Murcia, southern Spain, a poorly known area in the Mediterranean Sea, and it is compared with other close related species of the family Muricidae, such as O. nicolai (Monterosato, 1884), O. helleri (Brusina, 1865), O. vazzanai Crocetta, Houart et Bonomolo, 2020 and Ocinebrina reinai Bonomolo et Crocetta, 2012.
\end{abstract}

KEY WORDS Mollusca; Muricidae; Ocenebra aparicioae n. sp; Mediterranean.

Received 16.05.2020; accepted 18.06.2020; published online 30.06.2020

\section{INTRODUCTION}

After a series of recently published studies focused on the Ocenebra edwardsii complex (Barco et al., 2013a, 2013b, 2016) and on the Ocinebrina aciculata complex (Barco et al., 2017; Crocetta et al., 2012) and performed on the basis of molecular and morphological features, the cluttered situation of the subfamily Ocenebrinae Cossmann, 1903 in the Mediterranean Sea was partially clarified. The genus Ocinebrina Jousseaume, 1880 and Ocenebra Gray, 1847, that where until then considered monophyletic, are now separated in different clades, and the species attributed to the Ocinebrina edwardsii complex were placed in Ocenebra (Barco et al., 2016). These papers also led to some new combinations: Ocinebrina carmelae Cecalupo, Buzzurro et Mariani, 2008 as synonym of Ocenebra piantonii (Cecalupo, Buzzurro \& Mariani, 2008) (Barco et al., (2013b), the validation of Ocenebra hispidula (Pallary, 1904) as a distinct species
(Barco et al., 2013a) and the description of Ocinebrina reinai Bonomolo et Crocetta, 2012 in Crocetta et al. (2012) and Ocinebrina aegeensis Aissaoui, Barco et Oliverio, in Barco et al. (2017) as new species. However, Ocenebra nicolai (Monterosato, 1884), Ocenebra helleri (Brusina, 1865) and Ocenebra paddeui (Bonomolo \& Buzzurro, 2006) still need molecular analysis.

The study of the area of Isla del Fraile and other enclaves in the Hornillo Bay (Murcia) by scuba diving in precoralligenous and bioclastic bottoms led to the finding of several shells and living specimens of small muricids that did not fit with any known species and are here described as a new species. Considering plesiomorphic similarities with the Ocenebra edwardsii complex, like the colour of the animal, the presence of a varicose external lip, the shape, the sculpture of the shell and the absence of labral tooth (Barco et al., 2016) this newly described species is placed in the genus Ocenebra. 


\section{MATERIAL AND METHODS}

All the samples where handpicked during scuba dives in Isla del Fraile, a small close-shore island with coordinates $37^{\circ} 24^{\prime} 31^{\prime \prime} \mathrm{N}, 1^{\circ} 32^{\prime} 48^{\prime \prime} \mathrm{O}$ and other similar enclaves in the Hornillo Bay (Águilas, Murcia, Spain) at depths between -6 and -20 m on rocks in precoralligenous and bioclastic bottoms between October 2018 and November 2019.

The samples were studied and photographed under a stereo microscope and some specimens were maintained in aquarium for the study of the animal.

Nomenclature and systematics are applied based on MolluscaBase (2020).

ABBREVIATIONS AND ACRONYMS. Following Merle $(2001,2005)$ to define spiral sculpture: Abapical infrasutural secondary cord (abis); adapical infrasutural secondary cord (adis); infrasutural primary cord (IP); primary cord (P); secondary cord ( $\mathrm{s}$ ). Other abbreviations and acronyms: Author's personal collection (APC); maximum height $(\mathrm{H})$; Museo Nacional de Ciencias Naturales, Madrid, España (MNCN); Muséum National d'Histoire Naturelle, París, France (MNHN); maximum width of the last teleoconch whorl (W).

\section{RESULTS}

\section{Systematics}

Classis GASTROPODA Cuvier, 1795

Subclassis CAENOGRASTROPODA Cox, 1960

Superfamilia MURICOIDEA Rafinesque, 1815

Familia MURICIDAE Rafinesque, 1815

Subfamilia OCENEBRINAE Cossmann, 1903

Genus Ocenebra Gary, 1847

TYPE-SPECIES. Murex erinaceus Linnaeus, 1758 (by monotypy)

Ocenebra aparicioae n. sp. (Figs. 1-29) http://zoobank.org/f0e877c3-ac1a-4a6b-afa99f1bdc15c97f

TyPe LOCALITY. Hornillo bay, Águilas, Murcia, Spain, sciafilic-precoralligenous bottoms between -6 and -20 meters deep.
Etymology. The species is dedicated to the author's mother, Concepción Aparicio.

TyPe MATERIAL. Holotype $\mathrm{H}=9.18 \mathrm{~mm}, \mathrm{~W}=$ 4.75 mm (MNHN-IM-2000-35617) (Figs. 1-5); Paratype $1 \mathrm{H}=7.00 \mathrm{~mm} \mathrm{~W}=3.85 \mathrm{~mm}(\mathrm{MNCN}$ 15.05/XXXX) (Figs. 9, 10); Paratype $2 \mathrm{H}=9.29$ $\mathrm{mm} \mathrm{W}=5.15 \mathrm{~mm}$ (APC) (Figs. 11, 12); Paratype $3 \mathrm{H}=8.92 \mathrm{~mm} \mathrm{~W}=4.21 \mathrm{~mm}$ (APC) (Figs. 1819); Paratype $4 \mathrm{H}=8.72 \mathrm{~mm} \mathrm{~W}=4.13 \mathrm{~mm}$ (APC) (Figs. 13, 14); Paratype $5 \mathrm{H}=8.03 \mathrm{~mm} \mathrm{~W}$ $=4.14 \mathrm{~mm}$ (APC) (Figs. 16, 17). All from type locality.

OTHER STUDIED MATERIAL. Other 13 living specimens and other 21 shells, including 3 juveniles.

DESCRIPTION OF THE HOLOTYPE. Shell of small size for the genus, with $9.18 \mathrm{~mm}$ high and 4.75 wide. Solid and compact of romboidal/fusiform shape with 4.5 convex teleoconch whorls, last whorl consisting in $2 / 3$ of the total shell length. Protoconch paucispiral (Figs. 4, 5) with 1.25 whorls of $700 \mu \mathrm{m}$ in height and $600 \mu \mathrm{m}$ wide, with a dark brown color, rounded, with the nucleus inclined to the center around $30^{\circ}$, smooth surface with a very fine irregular granularity, observable only under high magnifications. Teleoconch amber yellow with a darker apex and dark brown spots on the tubercles. Spiral sculpture is strong and regular, consisting of adis-IP-abis-P1-s1-P2-s2-P3-s3-P4s4-P5-s5-P6-s6-ADP-MP-ABP (Fig. 15) in those shells where all cords are clearly manifested. Primary cords are much thicker and evident than secondary cords. P1 is the most prominent of the primary cords. Abis, s1, s4 and s6 are weaker and hardly noticeable, as well as the siphonal spiral cords, that are more diffuse, while adis, s2, s3 and s5 are the most evident secondary cords, and are always clearly present. There are 10 strong axial ribs in the last whorl and strong, thick, smooth and rounded nodes raise above the primary spiral cords when they overlie the axial ribs, giving it a cancellated/mamillated appearance, dark brown coloured, fading in the intercostal space. These tubercles appear also in the secondary cords, especially in adis, s2, s3 and s5. Suture is not deep, axial ribs generally touch between whorls. External lip with a thick and jagged varicosity. Siphonal canal short, strong, ventrally sealed in the adults by a sheet coming out the columelar edge. Aperture oval and narrow, white, with 5 internal denticles, equal in 
size (D1-D5). Columellar lip narrow and adherent, smooth and white. The soft parts (Figs. 6-8) present a translucent cream to yellow pigmentation, splashed with small shiny white-yellow spots concentrated in the foot and the tentacles, the latter being long, translucent and densely spotted with bright yellow especially from the eye to the end of the tentacle. Operculum corneus and eccentric, with a soft brown to orange colour.

VARIABILITY. As typical in the group, intraspecific variability is observable, but less markedly compared to other species of the genus.

The observed shell size range was between 7.52 to $10.30 \mathrm{~mm}$ high and 3.85 to $5.51 \mathrm{~mm}$ wide, with 4.5 to 5 teleoconch whorls. Axial ribs are between 9-11 in the last whorl, and rarely (only in 3 of the specimens studied) an erratic varicosity in the last whorl is observed. Abis, s1, s4 and s6 can sometimes be unnoticeable. The aperture in less mature shells can occasionally be pale brown or purple.

In some specimens the shape can be more rhomboidal-like or more fusiform. The colour of the shell can include the presence of a cream to white spiral line along P2 or in both P2 and P5, where the brown colour of the tubercles on these cords can fade with the white (Figs. 22, 23) or either still be present over the white band (Fig. 28, 29). It has also been observed the almost complete vanishing of all the brown spots on the tubercles, leading to a uniform amber colour, but this condition as only been observed in one specimen which could be considered old and sligthly eroded.

Distribution And Biology. The new species seems to have preferences to well developed scapes, with high bentic organism density (sciafilic/precoralligenous community) at depths between 6 and 20 $\mathrm{m}$ with moderate hydrodinamism and a complex geomorphology, where it appears on rocks highly affected by biologic activity, piled in such way they provide abundant wide shelters and space between them.

Compative Notes. The most similar related species to $O$. apariciae n. sp. is $O$. nicolai (Monterosato, 1884) whose sculpture tends to be less marked, more irregular and does not develop nodules, has a lower number of axial ribs and being the suture deeper, leading to more convex whorls. Ocenebra nicolai seems to be distributed in the Ionian, Thyrrhenian and Ligurian seas (Russo,
2018), however its presence should not be discarded in the Adriatic Sea, and in the Alborán Sea with an interesting red coral bottoms population in the Gibraltar strait, along the Morocco's side, which need further studies. Despite this, $O$. nicolai is not signaled in the coasts of Andalucía (Gofas et al., 2011) but it is considered as a possible deep water ecophenotype of $O$. edwardsii (Payraudeau, 1826). This could be explained by the fact that only a deep water or intermediate form of $O$. edwardsi $i$ was actually studied and not the actual $O$. nicolai, as could be argued by the specimen figured, which does not match well with the classical interpretation of this taxon.

Another similar species is O. helleri (Brusina, 1865), whose taxonomy is confusing and still under discussion (Russo, 2018). It is present in the Tyrrhenian and Adriatic seas, and recently cited in Hellenic waters (Mbazios et al., 2020) with a shell which tends to have a more elongated shape, also a deeper suture and more convex whorls, with a more prominent siphonal canal, presenting also a higher number of spiral cords and 6 up to 7 internal denticles, unlike $O$. aparicioae n. sp. that shows only 5 .

It is interesting to note that this species seems to share a homoplasic feature with Ocinebrina reinai Bonomolo et Crocetta, 2012 (Figs. 30, 31) in the presence of dark spotting on the nodes of the spiral cords, making the shells look similar at first sight, but easily distinguishable by the strong and jagged varix in the outer lip of $O$. aparicioae n. sp., being much weaker or absent and barely crenulated in $O c$. reinai. The difference between primary and secondary cords of the spiral sculpture is more obvious in $O$. aparicioae n. sp., resulting in a more cramped appearance on the sculpture of Oc. reinai. Ocinebrina reinai shows 6 to 7 internal denticles, while O. aparicioae n. sp. always shows 5. Other confirming aspect is the colouration of the animal that appears reddish in Oc. reinai and all the components of the Oc. aciculata complex, while it is translucent yellow in $O$. aparicioae n. sp.

During the printing phase of this article, the report of a new species of the genus Ocenebra was received: O. vazzanai Crocetta, Houart et Bonomolo, 2020. This new species seems to be endemic of a submarine cave of the Messina Strait area and shows a similar aspect with $O$. aparicioae $\mathrm{n}$. sp. However, O. aparicioae n. sp. differs from $O$. vazzanai in size, being much smaller, since $O$. vazzanai 


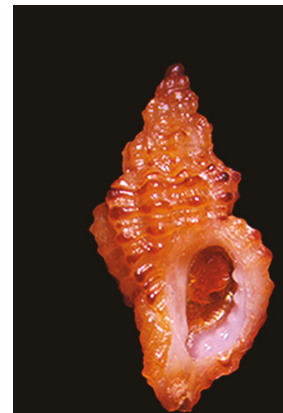

1

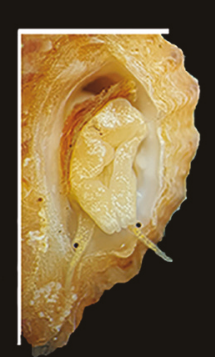

6

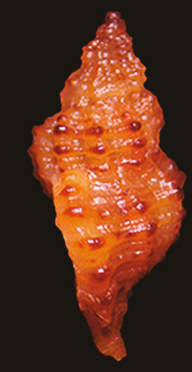

2

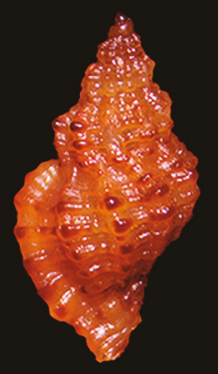

3

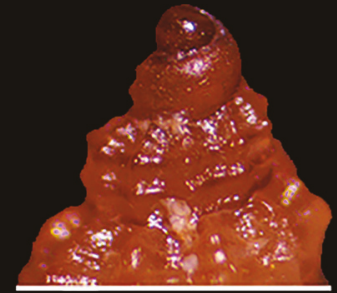

4

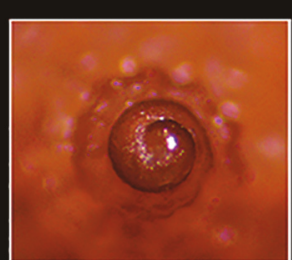

5

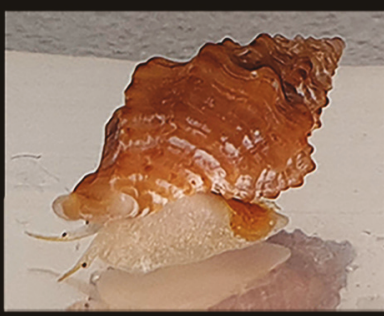

8

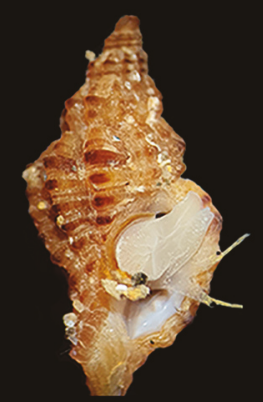

7

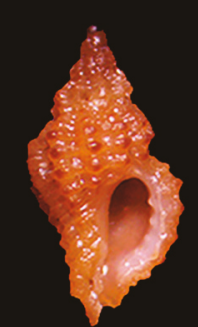

9

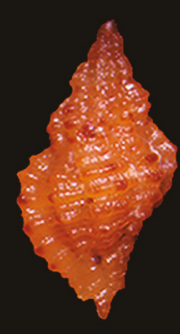

10

adis

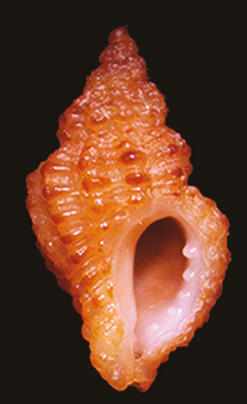

11

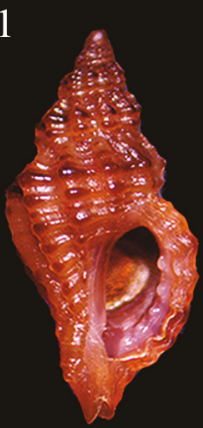

13
12

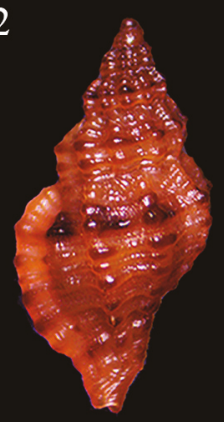

14

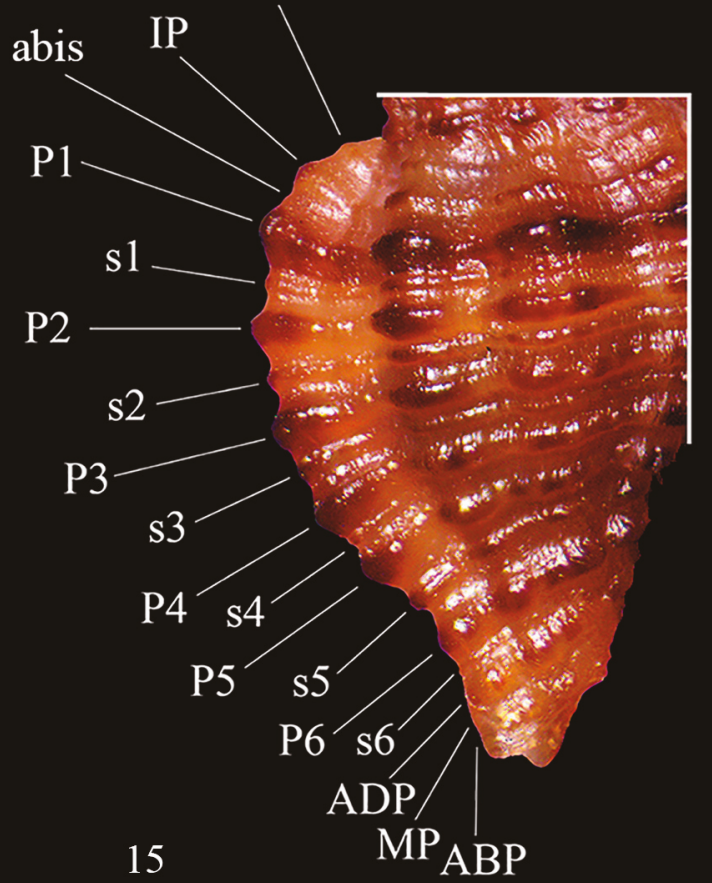

Figures 1-15. Ocenebra aparicioae n. sp., all from the type locality: Hornillo bay, Águilas, Murcia, Spain. Figs. 1-5: holotype, $\mathrm{H}=9.18 \mathrm{~mm} . \mathrm{W}=4.75 \mathrm{~mm}$. (MNHN). Figs. 4, 5: detail of the protoconch. Figs. 6, 8: detail of the animal. Figs. 9, 10: paratype $1, \mathrm{H}=7.00 \mathrm{~mm} . \mathrm{W}=3.85 \mathrm{~mm}$. (MNCN). Figs. 11, 12: paratype 2, $\mathrm{H}=9.29 \mathrm{~mm} . \mathrm{W}=5.15 \mathrm{~mm}$. Figs. 13, 14: paratype $4, \mathrm{H}=8.72 \mathrm{~mm}$. W $=4.13 \mathrm{~mm}$. Fig. 15: Outline naming the spiral sculpture of the last whorl. 


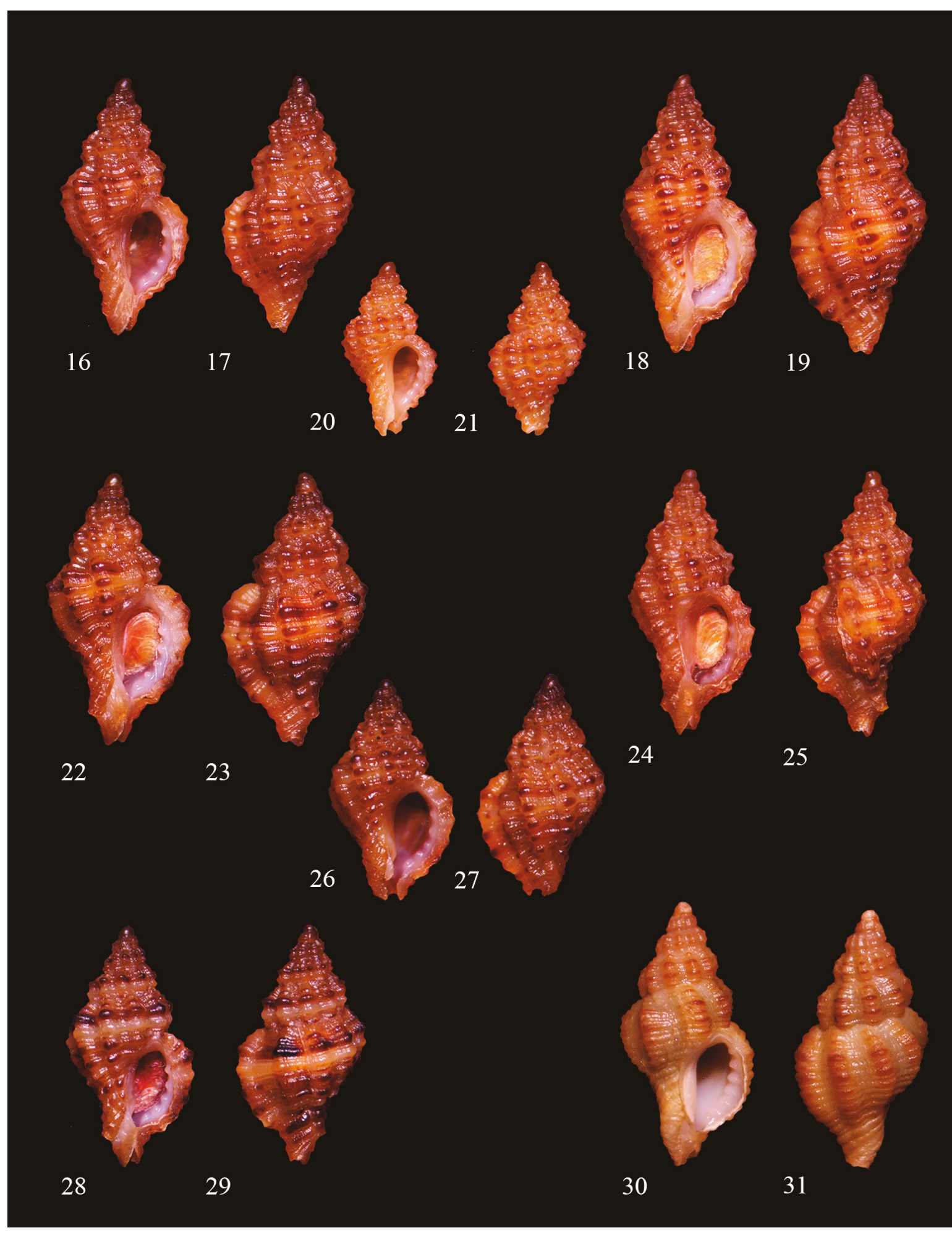

Figures 16-29. Ocenebra aparicioae n. sp., all from type locality. Figs. 16, 17. paratype 5, $\mathrm{H}=8.03 \mathrm{~mm}$. W $=4.14 \mathrm{~mm}$. . Figs. 18, 19: paratype $3, \mathrm{H}=8.92 \mathrm{~mm}$. $\mathrm{W}=4.21 \mathrm{~mm}$. Figs. 20, 21: juvenile $\mathrm{H}=6.50 \mathrm{~mm} . \mathrm{W}=3.31 \mathrm{~mm}$. Figs. $22,23: \mathrm{H}=$ $8.38 \mathrm{~mm} . \mathrm{W}=4.36 \mathrm{~mm}$. Figs. 24, 25: $\mathrm{H}=8.19 \mathrm{~mm} . \mathrm{W}=4.32 \mathrm{~mm}$. Figs. $26,27: \mathrm{H}=7.64 \mathrm{~mm} . \mathrm{W}=4.18 \mathrm{~mm}$. Figs. 28.29: $\mathrm{H}=7.88 \mathrm{~mm} . \mathrm{W}=4.34 \mathrm{~mm}$. Figs. 30, 31: Ocinebrina reinai Bonomolo et Crocetta, 2012, topotype $\mathrm{H}=9.77 \mathrm{~mm}$. W $=4.88$ $\mathrm{mm}$. Secche di Tor Paterno, $-35 \mathrm{~m}$. 
is in average twice as big and developes one more whorl, the colour, being the apex dark brown, is in contrast with the lighter teleoconch, while it is more uniform in $O$. vazzanai. The shape and sculpture are also different, as $O$. vazzanai shows a deeper suture, spiny appearance, specially in the last whorls, with a taller and more expanded labral varix and a wider apperture with a spiny edge. $O$. aparicioae also shows more spiral sculpture, with a prominent and always present adis. Habitat depth range seems to be also different, living $O$. vazzanai at around $50 \mathrm{~m}$ while $O$. aparicioae n. sp. has not been found under 20 meters.

As the shell of $O$. aparicioae n. sp. is so particular and does not resemble like any other not mentioned Mediterranean or northeastern Atlantic species, a comparision with other species is considered not required, excluding also the possibility of being an alien species.

\section{DISCUSSIONS AND CONCLUSIONS}

Evident morphological divergences have been observed between specimens studied and their congeneres and allowed to unequivocally distinguish and describe this taxon as new, being the most notable characters its small size, the marked regular axial and spiral sculpture leading to prominent and smooth nodes, the strong difference between primary and secondary cords and the constant tendency of this secondary cords to appear more or less marked depending on the sector, the shape and the striking colouration of the shell and soft parts. It is likely to complement with molecular analysis all these morphological characters above outlined in further studies.

Size is a remarkable factor, being this new species much smaller in average compared to its mentioned congeners. Considering only complete and adult specimens, the height average of the 34 shells measured is $8.78 \mathrm{~mm}$, with only 2 shells reaching one centimeter (max. height observed was $10.30 \mathrm{~mm}$ ) making it the smallest species of the genus.

In the studied area, at the lowest depth sampling ranges, few dead shells with hermit crabs of $O$. edwardsii were found, coming from shallower levels. These shells showed a thicker shell, with a much wider and purple aperture, clearly smaller proto- conch, lower spiral sculpture with a slight difference between primary and secondary cords, and a less numerous (7-8 axial ribs in the last whorl) but higher and broader axial sculpture. Despite the fact that $O$. edwardsii is a highly variable species, $O$. aparicioae $\mathrm{n}$. sp. does not fit to the characteristics of any of its forms.

Moreover, the shape and number of whorls of the protoconch of $O$. aparicioae seem to imply that a non planktotrophic larva is involved, which suggests a low dispersal capability of this species.

The new species seems to be rare, notwithstanding that the sampling was complicated by the environmental difficulties of the studied area especially in Isla del Fraile, where sciafilic algae and precoraligenous community dominate the bottom, and the abrupt geomorphism and the abundant calcareous organisms compound a complex seascape with many cracks and hiding places. The most abundant organisms in this community were represented by rhodophytic and pheophytic algae, colonial stony corals (Hoplangia durotrix Gosse, 1860), bryozooans as Myriapora truncata (Pallas, 1766), Reteporella grimaldii (Jullien, 1903) and Bugula sp., ascidians as Ascidia sp., Brotryllus sp., Clavelina sp., Didemnum sp., Halocynthia papillosa (Linnaeus, 1767)...), sponges as Clathrina sp., Cliona sp., Chondrosia sp., Crambe crambe (Schmidh, 1862), Dysidea sp., and Phorbas sp., Sycon sp., polychaetes and abundant bivalves attached to the rocks, like Barbatia barbata (Linnaeus, 1758), Arca noae Linnaeus, 1758, Cardita calyculata (Linnaeus, 1758), Striarca lactea (Linnaeus, 1758), Lima lima (Linnaeus, 1758), Mimachlamys varia (Linnaeus, 1758), Talochlamys multistriata (Poli, 1795) of which $O$. aparicioae n. sp. may feed upon. There are also gastropods such as Calliostoma sp., Gibbula sp., Jujubinus sp., Raphitoma sp., Alvania sp., Tritia sp., Naria spurca (Linnaeus, 1758), Luria lurida (Linnaeus, 1758), Fusinus cretellai Buzzurro et Russo, 2008, Muricopsis cristata (Brocchi, 1814), among others, compounding a very complex habitat ideal for many other species.

It is suitable to say that this specific habitat tastes, in addition to the lack of study of the area in this ambit and the probable limited range distribution due to a non planktotrophic development, may be the reason why this species was not noticed before. This reminds us that restricted and specific enclaves can be potential reservoirs for unknown 
species, even although being a species that lives close to the shore in shallow waters and belonging to a generally well known yet complex family in the Mediterranean as the Muricidae.

\section{ACKNOWLEDGEMENTS}

I am grateful to Alfredo Sánchez Hernández (Santander, Spain) from the International Prehistoric Investigation Institute of Cantabria (IIIPC) for the photo edition and to Lorena Gomariz Martínez (University of Murcia, Spain) for recommending me a photo editor, Dr. Ivan Mulero Mendez (Murcia, Spain) for participating in the sampling, Diego Moreno (Cabo de Gata, Almería, Spain) and Walter Renda (Amantea, Cosenza, Italy) for reading the manuscript and giving their valuable suggestions.

\section{REFERENCES}

Alfonso C.M.L., Bonomolo G., Monteiro P., Bentes., Oliveira F., Veiga P., Rangel M.O., Sousa I., Leite L. \& Gonçalves J.M.S., 2010. First Record of Ocinebrina nicolai (Mollusca: Gastropoda: Muricidae: Ocenebrinae) in north-eastern Atlantic waters. Marine biodiversity records, 3: 1-4. https://doi.org/10. 1017/S1755267210000631

Barco A., Corso A. \& Oliverio M., 2013a. Endemicity in the gulf of Gabés: the small mussel drill Ocinebrina hispidula is a ditinct species in the Ocinebrina edwardsii complex (Muricidae: Ocenebrinae). Journal of Molluscan Studies, 1-4. https://doi.org/ 10.1093/ mollus/eyt013.

Barco A., Houart R., Bonomolo G., Crocetta F. \& Oliverio M., 2013b. Molecular data reveal criptic lineages within the northeastern Atlantic and Mediterranean small mussel drills of the Ocinebrina edwardsii complex (Mollusca: Gastropoda: Muricidae). Zoological Journal of the Linnean Society, 169: 389-407. https:// doi.org/10.1111/zoj.12069

Barco A., Herbert G., Houart R., Fassio G. \& Oliverio
M., 2016. A molecular phylogenetic framework for the subfamily Ocenebrinae (Gastropoda: Muricidae). Zoologica Scripta, Royal Swedish Academy of Sciences. https://doi.org/10.1111/zsc. 12219.

Barco A., Aissaoui C., Houart R., Bonomolo G., Crocetta F. \& Oliverio M., 2017. Revision of the Ocinebrina aciculata species complex (Mollusca: Gastropoda: Muricidae) in the northeastern Atlantic Ocean and Mediterranean Sea. Journal of Molluscan Studies, 84: 19-29. https://doi.org/10.1093/mollus/eyx039

Crocetta F., Bonomolo G., Albano PG., Barco A., Houart R. \& Oliverio M., 2012. The status of the northeastern Atlantic and Mediterranean small mussel drills of the Ocinebrina aciculata complex (Mollusca: Gastropoda: Muricidae), with the description of a new species. Scientia Marina, 76: 177-189.

Crocetta F., Houart R. \& Bonomolo G., 2020. The More You Search, the More You Find: A New Mediterranean Endemism of the Genus Ocenebra Gray, 1847 (Mollusca: Gastropoda: Muricidae) from a Submarine Cave of the Messina Strait Area (Italy). Journal of Marine Science and Engineering, 8: 443, 16 pp. https://doi.org/:10.3390/ jmse8060443

Gofas S., Moreno D. \& Salas C., (coords.). 2011. Moluscos marinos de Andalucía. Volumen I, pp. 1-342. Málaga: Servicio de Publicaciones e Intercambio Científico, Universidad de Málaga, pp. 282.

Mbazios G., Kontadakis C., Galinou-Mitsoudi S. \& Manousis T., 2020. New gastropod records for the Mediterranean and the Hellenic Seas. Xenophora Taxonomy, 27, suplemento 169: 34-58

Merle D., 2001. The spiral cords and the internal denticles of the outer lip in the Muricidae: terminology and methodological comments. Novapex, 2: 69-91.

Merle D., 2005. The spiral cords of the Muricidae (Gastropoda, Neogastropoda): importance ofontogenetic and topological correspondences for delineating structural homologies. Lethaia, 38: 367-379. https:// doi.org/10.1080/00241160500355129

MolluscaBase eds., 2020. MolluscaBase. Muricidae Rafinesque, 1815. Accessed through: World Register of Marine Species at: http://www.marinespecies. org/aphia.php? $\mathrm{p}=$ taxdetails\&id $=148$ on $2020-03-30$

Russo P., 2018. Il genere Ocenebra Gray, 1847 (Gastropoda: Muricidae) nel Mare Mediterraneo. Alleryana, 36: 68-85. 
